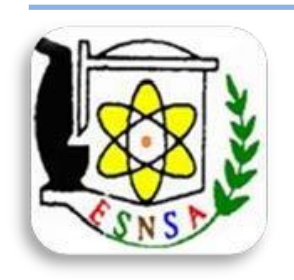

Arab Journal of Nuclear Sciences and Applications

ISSN 1110-0451

Web site: ainsa.journals.ekb.eg

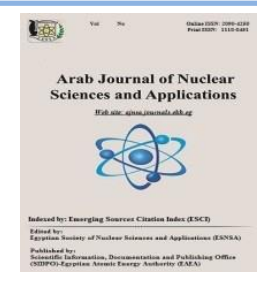

(ESNSA)

\title{
Biochemical and Histopathological Effect of Ultrasound Waves on Hepatic Tissue of Rats' Neonates
}

\author{
Aziza Amin and Mona H. Ibrahim* \\ Department of Pathology, Faculty of Veterinary Medicine, Benha University, Egypt \\ *Department of Physics, Faculty of Science, Zagazig University, Egypt
}

Received $20^{\text {th }}$ Jan. 2020

Ultrasound waves (US) has applications in various bio-medicine aspects. The current research was carried out to study the hematological parameters, biochemical and histopathological alterations in hepatic tissue post-exposure of pregnant rats to ultrasound waves. Eight pregnant mother rats were divided into two groups (four rats each). The first group was used as a negative control group that was not exposed to ultrasonic waves. The second group of pregnant mother rats was exposed to ultrasound waves with a nominal intensity of $0.2 \mathrm{~W} / \mathrm{cm}^{2}$ at the frequency of $(1 \mathrm{MHz})$ directly in contact with their bodies for $15 \mathrm{~min} /$ day through the last two weeks of the gestation period. Each mother gave 5 neonates. Then these neonates from each group were used for blood and tissue sampling. Some hematological parameters, Alanine aminotransferase (ALT), aspartate aminotransferase (AST), alkaline phosphatase (ALP) and total bilirubin in serum were evaluated. Samples of the liver in all groups were examined by light and transmission electron microscope for the detection of histopathological changes. Statistical evaluation of the results at a $p<0.05$ revealed a significant elevation in serum levels of AST, ALT, ALP, and total bilirubin, whereas hematological parameters were significantly reduced in the exposed group compared with the negative control one. Histopathologically, heavy leukocytic cellular infiltrations, degenerative and necrotic changes in the hepatocytes with mild hyperplasia of the lining epithelium of bile duct were demonstrated. The obtained results support the need for caution in the usage of ultrasound waves for repeated times, particularly during pregnancy.

Keywords: Ultrasound Waves, Neonatal Rats, Biochemical Evaluation, Histopathology, Transmission Electron Microscope

\section{Introduction}

Ultrasound (US) waves have been a vital tool in reproductive organs, cardiovascular system, ophthalmology, internal abdominal organs review. It is considered a thermal source. Ultrasound energy is used clinically for thermal tissue ablation, hemostasis, and thrombolysis and to promote tissue regeneration [1].

Ultrasound waves have frequencies above 20000 cycles per second. They are used in electronic, navigational, industrial, and security applications [2]. Depending on the frequency, ultrasound is divided into three types, among them the US ranging from 1 to $10 \mathrm{MHz}$ used for animal navigation and communication, detection of cracks or flaws in solids, and underwater echolocation, as well as diagnostic purposes. On the other hand, low birth weight can be attributed to early exposure to ultrasound [3] which may also induce alterations in density of bone elements [4], and a rise in fetal brain temperature [5].

US waves affect hematological parameters whether the ultrasound application either continuous or pulsed, the treatment frequency and intensity must be investigated [6]. The influences on blood under high stress or high-intensity ultrasound waves involve biological effects [7]. Erythrocytes counts differ significantly as well as

Corresponding author: mhmekky@yahoo.com

DOI: 10.21608/ajnsa.2021.27296.1341

C Scientific Information, Documentation and Publishing Office (SIDPO)-EAEA 
the concentration of hemoglobin and platelet count in newborns of Oryctolagus cuniculus post their exposure to US $\left(0.13\right.$ to $\left.0.19 \mathrm{~W} / \mathrm{cm}^{2}\right)$ for multiple periods during $3^{\text {rd }}$ trimester of pregnancy [8].

The liver is a very important organ that plays a vital role in body homeostasis, on metabolism, biotransformation, synthesis, storage, and immunology. The hepatocytes can be regenerated quickly. Consequently, the hepatic tissue can maintain its function until a certain level if there was a small destructed area. Meanwhile, in more severe disorders, malfunction of the hepatic tissue could be serious and fatal [9].

The advantages of ultrasound examinations include widespread availability, instructions for positioning the electrodes in real-time and accurate, convenient needle puncture guides. However, a major disadvantage of the current ultrasonic approaches is that the necrosis zone generated during the radiofrequency, microwave, or ultrasonic high-intensity ablation which is not accurately defined by trans-abdominal sonography occurs due to the difference in intrinsic contrast between normal and injured liver [10].

Therefore, the current work aims at highlighting the influence of ultrasound waves on the hematological, biochemical, and histopathological profiles in hepatic tissue in neonatal rats.

\section{Material and Methods \\ Animals}

Eight pregnant mother rats at the end of $1^{\text {st }}$ week of pregnancy were used to obtain the rat neonates required for this experiment. Rats were kept in a special plastic container of $15 \mathrm{~cm}$ width and $25 \mathrm{~cm}$ height. The topsides, and bottom of this container were available to permit proper ventilation away from any stressful stimuli with normal room conditions of temperature, humidity and to a 12-hr light/dark cycle and supplied with diet and water ad libtium throughout the experiment.

\section{Experimental Design}

Animals were randomly divided equally into two groups (4 rats each) namely, the negative control group (group 1) and the exposed group (group 2) in which the animals were exposed to irradiation by putting the ultrasound device (1 $\mathrm{MHz}$, $\left.0.2 \mathrm{~W} / \mathrm{cm}^{2}\right)$ in direct contact with the mothers' abdomen during the last two weeks of pregnancy. The animals received a whole-body ultrasound waves dose with a nominal intensity of $0.2 \mathrm{~W} / \mathrm{cm}^{2}$ at a frequency of $1 \mathrm{MHz}$ for $15 \mathrm{~min} /$ day for 2 weeks. Five neonatal rats were collected from each mother and kept for one-week post parturition. All experimental procedures were approved and performed by the study protocol appropriated by the ethical committee of the Faculty of Science, Zagazig University, Egypt, for animal care and experimentation.

\section{Hematological Assay}

Blood samples were collected from the pups of each group either on $0.2 \%$ EDTA anti-coagulant for evaluation of RBCs count and HB content and total leukocytic count and on ammonium oxalate anticoagulant for platelets count (PLT) using standard techniques according to Mitchell Lewis et al.[11].

\section{Biochemical Analysis}

For evaluation of hepatic tissue function, Aspartate aminotransferase (AST) and alanine aminotransferase (ALT) activities were estimated according to the method of Schumann [12]. Serum alkaline phosphatase (ALP) was measured following the protocol of Abicht et al. [13] and serum total Bilirubin was evaluated according to the method of Tietz [14].

\section{Histopathological Analysis}

Formalin-fixed liver samples from both groups were prepared for histopathological examination following the protocol of Bancroft et al. [15] where the dehydration of the samples was performed in a graded ethanol series, cleared in xylol and finally immersed in paraffin wax. Paraffin parts at $4-5 \mu \mathrm{m}$ were prepared and stained under the light microscope with hematoxyl and eosin stain (H\&E) according to Bancroft et al.[15].

\section{Transmission Electron Microscopic Examination}

Specimens of the liver from the negative control and exposed groups were fixed with $2.5 \%$ glutaraldehyde in phosphate buffer saline $(0.2 \mathrm{M}$, $\mathrm{pH} 7.4$ ) for $24 \mathrm{~h}$ at $4^{\circ} \mathrm{C}$, then in $1 \%$ osmium tetroxide for $2 \mathrm{~h}$ at $4^{\circ} \mathrm{C}$. Dehydration of the liver samples, using rated acetone followed by amyl acetate, was performed and then the samples were dried to a critical level with liquid carbon dioxide. Tissue samples were placed on stubs of sheet, gold sputter-coated thicknesses of around 20 $\mathrm{nm}$ and dried for $24 \mathrm{~h}$, and double-stained with uranyl acetate and lead citrate. The sections were examined with a transmission electron microscope (JOEL-JSM-5500 LV, Japan) at the central 
laboratory of the Faculty of Agriculture, Mansoura University according to Ali [16].

\section{Statistical Analysis}

The data were analyzed using a commercially available statistical software package (SPSS v. 22.0). Results were reported as \pm SD standard. The statistical significance was defined using the Student's t-test by the level $\mathrm{p}<0.05$.

\section{Results}

\section{Hematological Parameters}

A significant $(p<0.05)$ reduction in all blood parameters including a count of erythrocytes, leukocytes, and blood platelets as well as hemoglobin content of rat neonates obtained from group 2 in comparison to the control group (Table $1)$.

Table (1): Effects of ultrasound waves on hematological parameters of rat's neonates

\begin{tabular}{|c|c|c|}
\hline Blood parameters & Group 1 & Group 2 \\
\hline RBCs $\times 10^{6} / \mathrm{mm}^{3}$ & $7.07^{\mathrm{a}} \pm 0.43$ & $6.83^{c} \pm 0.15$ \\
\hline $\mathrm{WBCsx} 10^{3} / \mathrm{mm}^{3}$ & $9.20^{c} \pm 0.66$ & $6.08^{b} \pm 0.17$ \\
\hline HB (g/dl) & $13.30^{\mathrm{a}} \pm 0.01$ & $9.89^{c} \pm 0.21$ \\
\hline PLTs $\times 10^{3} / \mathrm{mm}^{3}$ & $9.8^{\mathrm{a}} \pm 0.07$ & $5.8^{\mathrm{c}} \pm 0.09$ \\
\hline
\end{tabular}

\section{Biochemical Analysis}

There was a significant increase in the levels of AST, ALT and ALP levels as well as total bilirubin levels in neonatal rats in group 2 in comparison to the negative control as shown in Table( 2).

\section{Histopathological Examination}

The liver of the control group showed a normal histological structure of the hepatic tissue (Fig. 1a). Meanwhile, there were marked histopathological alterations in the hepatic tissues of animals exposed to ultrasound waves (group 2) namely, characterized, dilatation and congestion of the central, portal veins and hepatic sinusoids, activation of Kuepfer's cells with thrombosis of portal blood vessels. Perivascular (Fig. 1b) and peri-ductal (Fig. 1c) mononuclear leukocytic cellular infiltrations mainly lymphocytes and few macrophages accompanied by hyperplasia of the lining epithelium of bile duct with its distension with eosinophilic debris as well as peri-ductal hemorrhage (Fig. 1d) was also demonstrated. There was a diffuse hydropic degeneration of the hepatocytes characterized by swollen, pale, vacuolated cytoplasm with pyknotic or absent nuclei (Fig. 1e). Multiple small focal areas of coagulative necrosis characterized by retention of hepatic cell outline with hyper-eosinophilic cytoplasm of hepatocytes and karyorrhectic nuclear changes were observed in the hepatic parenchyma (Fig. 1f). Moreover, focal areas of lytic necrosis, characterized by the disappearance of hepatocytes and replaced by erythrocytesdisplaced the hepatic parenchyma (Fig. 1g).

\section{Transmission Electron Microscopic examination}

Normal hepatocytes with centrally located nuclei and mitochondria were demonstrated in the liver of group 1 (Fig. 2a). Severe ultrastructural changes were noticed in the liver of animals exposed to ultrasound waves (group 2) as the alterations in hepatocytes were heterogeneously varied from different degrees of degeneration to total cytolysis and necrosis. Variable degrees of mitochondria degeneration were observed with disintegrated inner membranes and in some cases appeared dissolved into cytoplasmic vacuoles (Fig. 2b). Degenerative changes were demonstrated in cell organelles (Fig. 2c \& d) in association with scant low-density cytoplasm and the disappearance of glycogen particles. Additionally, a part of the nuclear chromatin migrated to the edges of the nucleus of the hepatocytes with lysis of cell organelles were also detected (Fig. 2e).

Table (2): Effect of ultrasound waves on liver enzymes (AST, ALT, and ALP) and total bilirubin of rat's neonates

\begin{tabular}{c|c|c|c}
\hline Biochemical parameters & group 1 & group 2 & P-value \\
\hline AST (u/l) & $131.83 \pm 1.22$ & $140.78 \pm 1.23$ & 0.01 \\
ALT (u/l) & $83.80 \pm 1.41$ & $102.35 \pm 0.16$ & 0.01 \\
ALP (u/l) & $221.62 \pm 1.34$ & $231.31 \pm 0.20$. & 0.03 \\
Total bilirubin (mg/dl) & $0.82 \pm 0.124$ & $1.159 \pm 0.44$ & 0.02 \\
\hline
\end{tabular}




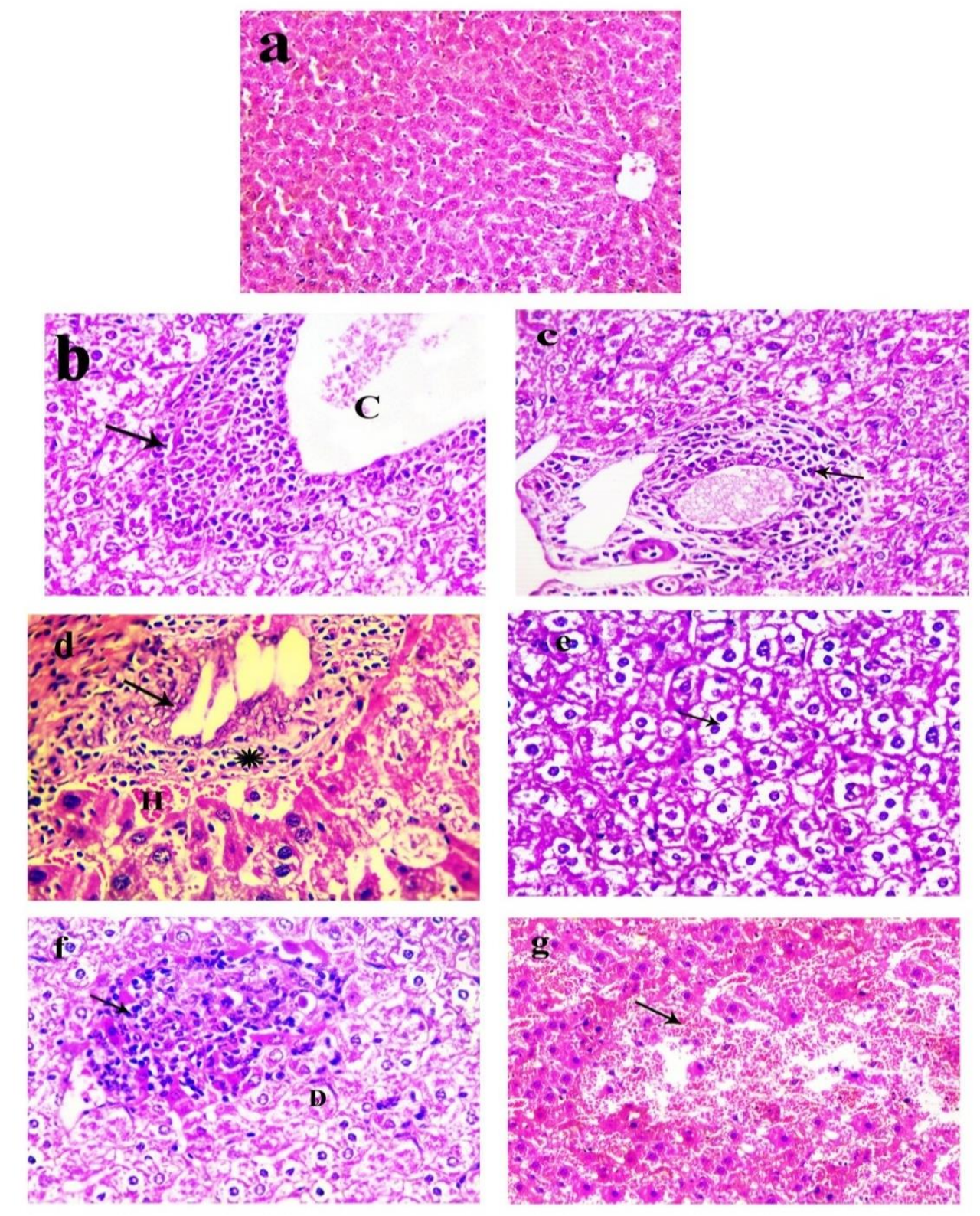

Fig. (1) : H\&E stained sections of liver tissue taken from group 1 (a) and group 2 (b-g) showing (a) normal histological structure of hepatic tissue $(\mathbf{x 1 0 0})$, (b) congestion of central vein $(C)$ with perivascular mononuclear leukocytic infiltration (arrow, x400), (c) marked periductal mononuclear leukocytic inflammatory cells aggregations (arrow) with luminal distension with eosinophilic debris (x400), (d) mild proliferation of the biliary epithelium (arrow) with periductal leukocytic infiltration (asterisks) and hemorrhage $(\mathbf{H}, \mathbf{x 4 0 0})$, (e) hydropic degeneration of hepatocytes characterized by swollen, pale, vacuolated cytoplasm with bi-nucleated hepatocytes (arrow, $\mathbf{x 4 0 0}$ ), (f) focal area of coagulative necrosis in the hepatic parenchyma (arrow, x400), (g) lytic necrosis, that characterized by loss of cord architecture and replaced by vacant space distended with erythrocytes (arrow, $\mathbf{x 4 0 0 )}$.

\section{Discussion}

Ultrasounds waves occur at frequencies above 20 $\mathrm{kHz}$ are a branch of sound waves and they exhibit all the characteristics and properties of sound waves [17]. Disorder or damage of hepatic tissue could be demonstrated from biomarkers such as AST, ALT, and ALP and a histopathological examination [9]. Therapeutic purposes of ultrasound waves were frequently described; meanwhile, little information is available about the effect of ultrasound waves on neonates. Therefore, the present work aims at studying the effect of ultrasound waves on the hematological, biochemical, and histopathological profiles in hepatic tissue in neonatal rats.

The results of the current research indicate that a significant reduction in hematological parameters including the count of erythrocytes, leukocytes 


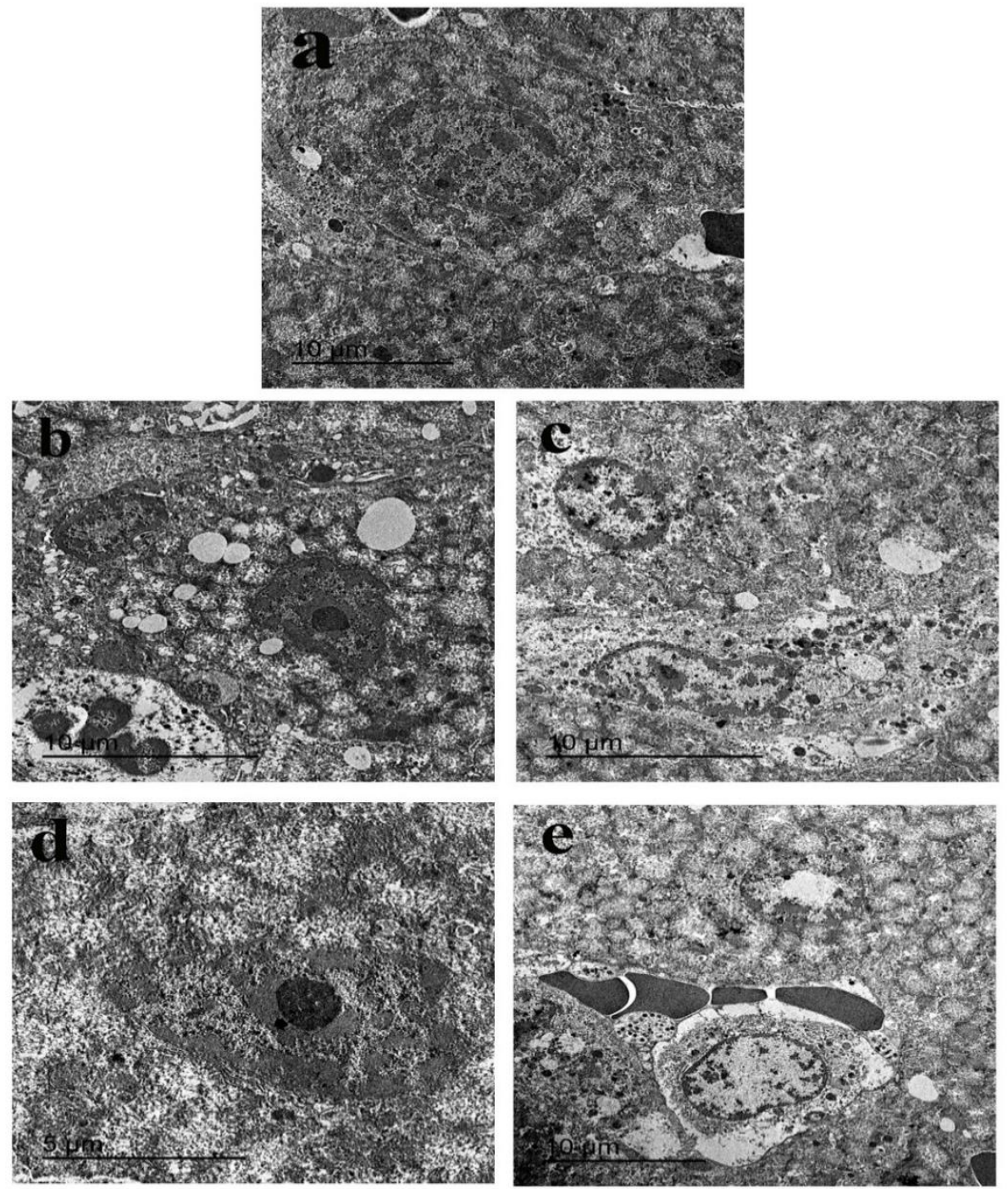

Fig.(2): Transmission electron sections of liver tissue taken from group 1 (a) and group 2 (b-e) showing (a) normal hepatic cells with a centrally located nucleus, (b) variable degree of mitochondrial degeneration, (c) degeneration of cell organelles, (d) cytoplasmic degeneration, (e) nuclear degeneration with margination of the chromatin with lysis of cell organelles in hepatocytes.

and blood platelets as well as hemoglobin content in the exposed animals 15 min per day for 2 weeks. These results could be attributed to the ability of ultrasound waves to cause a heat stress on the exposed tissue as increasing body temperature, regions of the RBC surface that are free of lipids become exposed and leaky, leading to wider hemorrhage and hemolysis [14]. In addition, a decline in the RBC production can be caused by continued exposure to ultrasound waves that induce bone marrow suppression [18]. Additionally, Ultrasound wave-induced hyperthermia may cause significant changes in blood properties, especially $\mathrm{Hb}$ [19]. When RBCs are damaged, $\mathrm{Hb}$ escapes into the plasma and causes depletion of iron which results in anemia
[20]. Interestingly, a significant elevation in the total bilirubin was also detected in the rats' neonates exposed to the US in the current research. The elevated bilirubin level is a consistent sign of injury of hepatic tissue or weakened hepatic bile flow, destruction of erythrocytes, or reduction in bilirubin metabolism [21]. Meanwhile, the reduction in the total leukocytic count detected in ultrasound exposed animals could be due to US waves that promotea reduction in total leukocytic count via inhibition of white blood cell proliferation [22].

Some biomarkers such as AST, ALT, ALP in association with histopathological examination could be used as indicators for hepatic tissue injury [9]. In the current study, a significant elevation in 
serum level of hepatic enzymes (ALT, AST, and ALP) was reported. The increase in these hepatic markers in animals exposed to US waves could be because of the rupture of the hepatic cell with loss of functional integrity of the cell membrane and cellular leakage leading to the release of these enzymes from the damaged hepatocytes. Furthermore, a significant increase in the ALP may be resulting from the elevated biliary pressure and acute cell necrosis caused the release of ALP from its membranes bound site and its entry into blood $[23,24]$.

In the present work, the normal histological structure of the hepatic tissue was observed in animals of the negative control group by light and transmission electron microscope. Meanwhile, the microscopic examination of the liver tissue in the group exposed to US waves revealed variable pathological alterations including severe degenerative changes, necrosis of the hepatic parenchyma with an inflammatory reaction, hemorrhage, and hyperplasia of the biliary epithelium detected by light and electron microscope. These obtained results could be confirmed by the increase in liver enzymes associated with a damage to the hepatocytes. However, these enzymes are considered excellent markers of cellular necrosis, as they are cytoplasmic enzymes [25]. However, Extra and additional details about the histopathological alterations in the hepatic tissue were evaluated by transmission electron microscope (TEM) as, these histopathological alterations in the hepatic tissue could be returned to mitochondrial dysfunction that may be generated by the disruption of $\beta$-oxidation of lipids and oxidative energy production within the hepatocytes. Moreover, a rupture in the mitochondrial membrane can lead to ATP depletion and consequent necrosis of the hepatic tissue [26]. Furthermore, ultrasound treatment produces an effect on the tissues via the generation of vibrations in the tissue components resulting in movements or displacements of tissue particles. Additionally, these vibrations have thermal and non-thermal effects on the biological tissues, the energy attenuated by tissues leads to increasing the thermal effects on the exposed tissues [27]. Consequently, ultrasound waves can affect cell membrane permeability, cell adherence, and cell proliferation [28] and they could lead to a loss of cell membrane integrity, which results in a disturbance in the normal structures and functions of plasma membranes.
In conclusion, ultrasound waves disturb the structure and function of the hepatic tissue of rats' neonates. These findings highlight the necessity for exercising caution while using ultrasound waves for repeated times, particularly during pregnancy.

\section{References}

1. Ter Haar, G. (2000) Intervention and Therapy, Ultrasound Med. Biol., 1, 51-4.

2. Demirel, R., Mollaogiu, H., Yesilyurt, H., Ucok, K., Aycicek, A. and Akkaya, M. (2009) Noise Induces Oxidative Stress in Rats, Eur. J. Gen. Med., 6, 20-24.

3. Gershfeld, N. L. and Murayama, M. (1988) Thermal Instability of Red Blood Cell Membrane Bilayers: Temperature Dependence of Hemolysis, J. Member. Biol., 101, 67-72.

4. Dom, S. (2013) Teratogenic effects of diagnostic ultrasound exposure, LAP LAMBERT Academic Publishing, Deutschland.

5. Andreassi, M. G., Venneri, L. and Picano, E. (2007), Cardiac imaging: the biological effects of diagnostic cardiac ultrasound, Prog. Biophys. Mol. Biol. 93, 399-410.

6. Signori, L.U., de Oliveira Teixeira, A., da Silva, A.M.V., da Costa, S.T., Dipp, T., Plentz, R.D.M. (2014) Effects of Therapeutic Ultrasound on Hematological Dynamics and Fibrinogen During the Inflammatory Phase after Muscle Injury in Rats, Acta Scientiarum.Health Sciences, 36, 25-31.

7. Paul, R., Apel, J., Klaus, S., Schugner, F., Schwindke, P. and Reul, H., (2003) Shear stress-related blood damage in laminar coquette flow, Artif. Organs, 27, 517-529.

8. Ahmad Zaki, F. W., Md Dom, S., Abdul Razak, H. R. and Hassan, H. F. (2013) Prenatal Ultrasound Heating Impacts on Fluctuations in the Hematological Analysis of Oryctolagus Cuniculus, Quant. Imaging Med. Surg., 3, 262-268.

9. Depkes, RI. (2007) Keputusan Mentri Kesehatan RI No: 900/MENKES/VII/2007, Konsep Asuhan Kebidanan. Jakarta.

10. Solbiati, L., Goldberg, S. N., Ierace, T., Livraghi, T., Meloni, F., et. al. (1997) Hepatic metastases: percutaneous radio-frequency ablation with cooled-tip electrodes, Radiology, 205, 367-373.

11. Pagana, K. and Pagana, T. (2018) Mosby's Manual of Diagnostic and Laboratory Tests, Published by St. Louis, Elsevier.

Arab J. Nucl. Sci. \& Applic. Vol. 54, No. 1 (2021) 
12. Schumann, G., Bonora, R., Ceriotti, F., et al., (2002) IFCC Primary Reference Procedures for the Measurement of Catalytic Activity Concentrations of Enzymes at 37 Degrees C. International Federation of Clinical Chemistry and Laboratory Medicine. Part 5. Reference Procedure for the Measurement of Catalytic Concentration of Aspartate Aminotransferase, Clin. Chem. Lab. Med., 40(7), 725-33.

13. Abicht, K., El-Samalouti, V., Junge, W., et al., (2001) Multicenter evaluation of new GGT and AIP reagents with new reference standardization and determination of reference intervals, Clin. Chem. Lab. Med., 39 (Special Supplement) S 346.

14. Tietz, N.W. (1995) Clinical Guide to Laboratory Tests, $3^{\text {rd }}$ ed Philadelphia Pa, W.B. Saunders Company London, 130-131.

15. Bancroft, J., Stevens, A. and Turner, D., (1996) Theory and Practice of Histological Techniques, $4^{\text {th }}$ ed Churchill Living Stone, New York Edinburgh. Madrid, Sanfrancisco.

16. Ali, M. H. E. (2013) Histopathological and Histochemical Studies on The Effect of Curcumin on The Liver of Rats, M.Sc. Thesis, Faculty of Science. Zagazig, University. Egypt.

17. Raj, B., Rajendran, V. and Palanichamy, P., (2004) Science and Technology of Ultrasonics. Pangbourne, UK.

18. Mehrpour, M., Shakeri-Zadeh, A., Basir, P., Jamei, B., Ghaheri, H. and Shiran, M. B. (2016) Effects of Low-Intensity Continuous Ultrasound on Hematological Parameters of Rats, J Biomed PhysEng, 6(3), 195-200.

19. Drury, R. and Wallinigton, E. (1980) Carleton's Histological Technique, 4th Ed. Oxford. Univ. Press, New York, Toronto, 115119.

20. Davies, MJ. (1990) A Macro and Micro View of Coronary Vascular Insult in Ischemic Heart Disease, Circulation, 82 (3 Suppl), II 38-46.

21. Boone, L. I., Meyer, D. J., Cusick, P., Ennulat, D., Provencher Bollinger, A., et al. (2005)
Selection and Interpretation of Clinical Pathology Indicators of Hepatic Injury in Preclinical Studies, Vet. Clin. Pathol, 34, 182188.

22. Costa, S.T., Lauxen, J., Sturzenegger, T.M., Signori, L.U. and Plentz, R.D. (2006) Efeito Anti-Inflamatorio Do Ultra som De $1 \mathrm{Mhz} \mathrm{Na}$ Dinamica Hematologica, Rev Bras Fisioter, 10 (1), 60-1.

23. Hassan, H. A., EL-Kholy, W. M. and Galal, N. A. (2015) Comparative Protective Effect of Moringa and Dandelion Extracts Against Hepatic Disorders and Oxidative Stress Associated with Prolonged Use of Brufen Drug in Rats, The Egyptian Journal of Hospital Medicine, 60, 336-346.

24. Al- Madany, N. A. and Sarhat, E. R. (2018) Determination of Some Biochemical Parameters of Patients with Hepatitis B in Kirkuk City, KUJSS, 13(2),139 -148.

25. Sarhat, E. R., Wadi, S. A. and Ibrahim, S. K. (2016) The Influence of Lycopene on Interleukin-6, Tumor Necrosis Factor $-\alpha$, Alanine Aminotransferase, Aspartate Aminotransferase Levels In StreptozotocinInduced Diabetic Rabbits, 3rd Scientific Conference - College of Veterinary Medicine University of Tikrit, 1-5.

26. Alejandra Cano Paniagua and Pedro Amariles, (2018) Pharmacokinetics and Adverse Effects of Drugs - Mechanisms and Risks Factors. Chapter 5, 77-92.

27. Claes, L. and Willie, B. (2007) The Enhancement of Bone Regeneration by Ultrasound, Prog Biophys Mol Biol, 93, 384398.

28. Feril, L.B., Tachibana, K., Ogawa, K., Yamaguchi, K., Solano, IG. and Irie, Y. (2008) Therapeutic Potential of Low-Intensity Ultrasound, part 1: Thermal and Sonomechanical Effects, J Med Ultrason, 35, 153-160 